\title{
Robotik Total Station ve GNSS Ölçümlerinin Analizi
}

\author{
Hüseyin Pehlivan \\ Gebze Teknik Üniversitesi, Harita Mühendisliği Bölümü, Gebze-Kocaeli. hpehlivan@ gtu.edu.tr
}

Geliş / Received: 19/03/2019, Kabul / Accepted: 29/03/2019

\begin{abstract}
$\ddot{\mathbf{O} z}$
Bu çalışmada, yapıların bağıl deplasmanlarının belirlenmesinde, Robotik Total Station (RTS) ve Global Navigation Satellite System (GNSS) ölçümlerinin kullanılabilirliği araştırılmış ve deneysel verilerle analiz edilmiştir. Bu amaçla, İstanbul'da bulunan yüksek bir yapının gözlemlenebilir yükseklikte tepesine, iki adet GNSS alıcı anteni ve Total Station prisma reflektörleri monte edilmiştir. Bu iki gözlem noktasında, Gerçek Zamanlı GNSS ölçümleri ve yaklaşık $520 \mathrm{~m}$ uzaklıkta bulunan izleme noktalarından iki adet RTS kullanılarak açı-mesafe-zenit öçümleri, eş zamanlı olarak gerçekleştirilmiştir. Böylece, kayıt edilen bu gözlem serileri analiz edilerek yapının salınım genliklerinin belirlenmesi ve karşılaştırılması hedeflenmiştir. Analiz sonucunda şu sonuçlar elde edilmiştir; GNSS ölçümleri ile centimeter doğrulukla 0.5-1 cm genlikli salınımlar belirlemek mümkün olmuşken, RTS ölçümleri ile birkaç mm doğrulukla (2 mm) genlikli salınımlar kayıt edilebilmiş ancak yüksek frekanslı yerdeğiştirme değerleri belirlenememiştir. Bu sonuçlar, otomatize edilen Elektronik Totalstation'ların GNSS'e bir alternatif olarak yapı deplasmanlarının belirlenmesinde kullanılabilirliğini göstermiştir.
\end{abstract}

Anahtar Kelimeler: GNSS, Total Station, RTS, Zaman Serisi, Deplasman.

\section{Robotic Total Station and Analysis of GNSS Measurements}

\begin{abstract}
In this study, the usability of the Robotic Total Station (RTS) and Global Navigation Satellite System (GNSS) measurements in the determination of the relative displacements of the structures were investigated and analyzed with experimental data. For this purpose, two GNSS receiver antennas and Total Station prisma reflectors were installed at the observable height of a high structure in Istanbul. At these two observation points, Real Time GNSS measurements and angle-distance-zenite measurements were performed simultaneously using two RTSs from the monitoring points located at a distance of approximately $580 \mathrm{~m}$. Thus, the time series of these observations were analyzed to determine and compare the amplitude of oscillation of the structure. As a result of the analysis, the following results were obtained; While it was possible to determine the oscillations of $0.5-1 \mathrm{~cm}$ amplitude with the centimeter accuracy with GNSS measurements, the oscillations with amplitude with a few $\mathrm{mm}$ accuracy $(2 \mathrm{~mm})$ with RTS measurements could be recorded but high frequency displacements values could not be determined. These results demonstrated the availability of automated Totalstation systems for the determination of structural displacements as an alternative to GNSS.
\end{abstract}

Keywords: GNSS, Total Station, RTS, Time Series, Displacement. 


\section{Giriş}

Yapısal izleme çalışmalarında, mühendislik yapıları, kule, köprü ve barajlarda son on yılda çok sayıda uygulamalar yapılmıştır. GNSS ölçümleri yapısal izlemede kullanılan başlica metodlardan biridir. GNSS ölçümlerinden başarılı sonuçlar alınabilmesi, uydu görünürlüğünün kesintisiz olmasına bağlıdır. GNSS ile köprü ve baraj gibi yüksek yapılarda başarılı çalışmalar yapılmasına rağmen, kule benzeri yapılarda gürültülü veriler elde edilmiştir. Bu nedenle kule yapilarda deplasman belirleme çalışmalarında klasik ölçme aletleri ile entegrasyonlu kullanımları geliştirilmiştir (Pehlivan, 2009). Özellikle kule duvarlarının uydu sinyallerini engelemesi ve yansitmasi (multipath oluşması) gibi nedenlerle, kule yapıların yanal yüzlerinde monte edilen GNSS alıciları ile hesaplanan konum değişimleri küçük genlikli salınımların belirlenmesini engellemektedir. Bunun yanısıra özellikle kurulum maliyetleri ve GNSS'in teknik özelliğinden kaynaklanan sorunlar nedeniyle, uydu ölçme tekniklerinin yetersiz kaldığ 1 durumlarda klasik ölçme metodu olan açı ve mesafe ölçümlerini, alternatif bir ölçme metodu olarak, total stationların kullanımını ön plana çıkarmıştır (Greulich, 1997; Guo vd., 2005; Chan vd., 2006).

Yapı davranışlarının izlenmesinde kullanılan; elektronik açı-uzunluk ölçerler, yükseklik fark1 ölçerler, fotogrametrik teknikler, geoteknik ölçmeler ve diğer deformasyon belirleme teknikleri (interferometreler ve fiber optik sensörler) klasik ölçme yöntemleri olarak adlandırılır. Klasik ölçme yöntemleri, yapıların ulaşılabilir kısmının yatay ve düşey deformasyon oranı ve büyüklüğünü izlemek için uygulanabilir. Çoğu durumda uzun periyotlu izlemeler için uygundur. Eğer ölçme noktaları ulaşılamaz durumda ise yada daha yüksek bir doğruluk gerektiriyorsa geoteknik ölçme aletleri de bir alternatif olabilir (Pehlivan, 2009; Xia vd., 2005; Stiros vd., 2008; Erol, 2010).

Bir yapının doğal deplasman değerlerini ölçmenin sadece bir yöntemi yoktur. İncelenen binadan bağımsız olarak tanımlanan belli bir koordinat sistemi referans kabul edilerek, herhangi bir ölçme tekniği kullanılarak deplasmanlar ölçülebilir. İlk olarak 1880'li yıllarda, Paris'te bulunan Eyfel Kulesi'nin tepesinin salınımlarını gözlemlemek için teodolitler kullanılmıştır. $\mathrm{Bu}$ güne geldiğimizde, servo motor özelliği ile hedefe yönelebilen ve otomatik ölçümleri gerçekleştirebilen bir RTS ile yap1 hareketlerinin belirlenmesi yapısal izlemede kullanılan başlıca klasik ölçme aletlerinden olmuştur. İlk olarak, yeni teknoloji ürünü Robotik teodolitler kısa açıklığa sahip köprülerin $\mathrm{mm}$ doğrulukla deplasmanlarını ölçmekte kullanılmıştır. Bu sayede, rüzgar ve trafik yükü gibi dinamik yüklerden dolayı oluşan deplasmanların ölçülmesi ve mühendislik yapılarının sağlı̆̆ının değerlendirilmesi de mümkün olmuştur (Psimoulis ve Stiros, 2011). RTS'ler yapisal izleme çalışmalarında ilk olarak demiryolları üzerinde bulunan kısa demir yolu köprülerinin deplasman genliklerinin ölçülmesinde kullanılmıştır. Yunanistan'da bulunan bir köprüde, tren geçmiyorken 1.3 mm'ye kadar titreşimler ölçülürken, tren geçerken 2.5-6 mm'ye kadar olan sapmalar ölçülebilmiştir. Bu çalışma ile rijit köprülerin dinamik deplasmanlarının, RTS ile belirlenebileceği sonucuna varılmıştır (Panos vd., 2012).

Bununla birlikte, son zamanlarda jeodezik aleteri yeni jenerasyon ölçme aletleri ile desteklenen ivmeölçer, eğimölçer, GNSS ve bazen RTS yada robotik teodolitler (RT) 
ölçme sistemlerinde kullanılmaya başlanmıştır. Böylece, sadece dinamik hareketleri değil aynı zamanda statik ve yarıstatik yap1 hareketlerin belirlenebilmesi de sağlanmıştır (Ge vd., 2000; Brownjhon vd., 2005; Kontogianni vd., 2007; Psimoulis ve Stiros, 2007; Psimoulis ve Stiros, 2008; Lienarth vd., 2016; Izvoltova vd., 2014). İzlenen yapıların spektral karakteristiklerini belirleyebilmek için kullanılan bu jeodezik aletlerin en büyük avantajı kullanım kolaylığ 1 ve düşük maliyetli ölçme imkanı sunmasıdır (Xu vd., 2002; Brownjohn vd., 2005; Psimoulis ve Stiros, 2007; Psimoulis vd., 2008; Moschas ve Stiros, 2011).

RTS ile günümüze kadar, Navigasyon ölçümleri, Kadastro ve jeodezik ölçümler, deformasyon ölçümleri, yapı inşaat ölçümleri, mekanik ürünlerin geometrik doğruluklarının belirlenmesi gibi çok çeşitli çalışmalar yapılmıştır. Son yıllarda yapısal izleme alanında yapılan bazı çalışmalar ise şöyledir.

- GNSS ve RTS nin potansiyelinin değerlendirilmesi, accelerometerler ile desteklenmesi, çeşitli mühendislik yapılarının salınımarının ölçülmesi (deney ve veri analizleri).

- Modal frekansi $1 \mathrm{~Hz}$ den büyük ve subcentimeter genlikli rijit yapıların jeodezik ölçümlerinin ölçme aralığının artırılması-geliştirilmesi.

- Jeodezik zaman serilerinin filtrelenmesi ve spektral analizi için algoritmalar ve yeni tekniklerin geliştirilmesi.

- Köprülerin yanal salınımlarının ölçülmesi.

- Yaşlanma/bozulma nedeniyle yapıların dinamik özelliklerinin varyasyonlarının tanımlanması ve ölçülmesi.

- Çeşitli mühendislik yapılarının rüzgar ve güneş etkisinde salınımlarının ölçülmesi ve analizi (asma köprü, pilon vs.).

$\mathrm{Bu}$ çalışmada; GNSS ve Totalstation ölçme yöntemleri eşzamanlı kullanılarak, bir kulenin statik ve yarı-statik deplasmanlarının belirlenmesi amaçlanmıştır. Bu amaçla, iki adet çift frekanslı GNSS alıcı anteni (NovAtel) monte edilmiştir. Bu iki adet GNSS antenine aynı doğrultuda prizma monte edilerek, iki adet Elektronik Total Station (Geodimeter 610S) ile yaklaşı 580 m uzaklıktan gözlemler yapılmıştır. Gözlemler 6 saat süreyle eşzamanlı olarak kayıt edilmiştir. GNSS alıcılarından uydu bazlı göksel referans sisteminde koordinatlar (3D), total stationlar ile doğrultu açıları (yatay-düşey) ve eğik mesafe gözlemleri kayıt edilmiştir. Böylece yapının konum değişimleri iki farklı yöntemle belirlenmiş ve ölçme doğruluğu açısından değerlendirilmiştir. (Pehlivan, 2009, Pehlivan vd., 2013). Bu çalışmanın sonucunda, uzun mesafeden RTS gözlemlerinin GNSS ölçümleri ile aynı doğruluğu yakalamasada alternatif olarak kullanılabilirliği görülmüştür. Bir yapının uzun zaman içindeki davranışı, RTS ile de düşük örnekleme oranı ile ölçülebilmektedir.

\section{Elektro-Optik Total Station ve} Robotik Total Station Ölçümleri

Elektronik Teodolitler (ET) yada Total Stationlar (TS), prizmatik bir reflektör yardımı ile işaretlenen seçili noktaların kartezyen koordinatlarını hesaplamak için yaygin olarak kullanılır. TS'ler teodolitlerin geliştirilmesi ile ortaya çıkmıştır. Ölçülen büyüklüklerin otomatize edilmesi ile yeni nesil aletlerde ortaya çıkmıştır (Schofield ve Breach, 2007). TS'ler yatay-düşey doğrultu ve mesafe ölçümlerini gerçekleştirdiğimiz jeodezik ölçme aletidir. Bir TS ölçümü, reflektöre yönlendirilmiş bir kızılötesi (InfraRed-IR) 1şını yayılır ve bu 1şın tekrar TS'ye döner, yayılan ışııın 'uçuş süresi' 'time-of-flight' (TOF) ölçülür ve böylece 
TS'nin reflektöre olan mesafesi hesaplanır. Bundan başka, TS noktasından seçilen noktaya olan zenit ve yatay doğrultu açıları da ölçülür. Böylece durulan istasyon noktasından, bakılan hedef noktasının ölçülen kutupsal koordinatları daha sonra seçilen bir referans sisteme göre milimetre ve hatta milimetre altı doğrulukla Lokal Kartezyen Koordinatlara dönüştürülür.

Total Stationlar yeryüzü ölçmelerinde kullanılan yüksek doğruluklu optikelektronik aletlerdir ve yaygın olarak kullanılmaktadır. RTS'ler ile gözlem noktasından ölçülecek noktalara olan mesafe ve açı değerleri belirli aralıklarla otomatik olarak ölçülebilmektedir. Modern RTS'ler, açı değerini $0.5^{\mathrm{cc}}$ ile ölçebilir. Normal totatl stationlar ile $5-10^{\mathrm{cc}}$ aralığında açı ölçümleri gerçekleştirilebilirken, hassas mesafe ölçümleri $0.1 \mathrm{~mm}$ doğrulukla ve normal arazi ölçmleride $1 \mathrm{~mm}$ doğrulukla gerçekleştirmek mümkün olmaktadır.

TS ile doğrultu ölçümleride en önemli konulardandır. Açı doğrultu ölçümleri cihazlara entegre edilen özel kodlanmış gonyometreler kullanılarak optik elektronik algılama yöntemi ile ölçülür. Bir diğer önemli ölçme parametresi ise mesafedir, ölçümünde genellikle iki yöntem kullanılır. Faz veya dürtüsel mesafe ölçme yöntemleri kullanılır. Faz mesafesi ölçümleri iletilen ve yansıyan sinyalin faz farkı ölçümlerine dayanır. Dürtüsel mesafe ölçümünde ise yansıyan sinyalin iletilmesi ve alınmasında farkın zamana bağlı korelasyonu ölçülür.

RTS veya Robotik teodolitler, TS'nin modern bir versiyonudur. RTS'ler hedef noktaya yönlenme ve ölçme işlemini otomatik olarak gerçekleştiri ve kayıt eder. İstenilen hedeflere yönelme ve kayıt etme işlemi, kullanılan programın özelliğine göre istenilen ölçme aralıklarında gerçekleştiriebilir. RTS ile 5-10 $\mathrm{Hz}$ frekans aralığında ölçülebilen hareketli bir reflektör izleyenebilir yada belirlenmiş bir zaman aralığında belli reflektörlere yönelme sağlanarak ölçümler gerçekleştirilebilir. Bu avantajlarından dolayı, RTS çok sayıda ölçme ve diğer mühendislik projelerinde yaygın olarak kullanılmaktadır (Psimoulis ve Stiros, 2008; Moschas vd., 2013; Lienarth vd., 2016). RTS'ler bu özelliklerinden dolayı genel mühendislik araştırmalarının yanısıra, daha bilimsel deneylerde de, $1 \mathrm{~Hz}$ den büyük yüksek frekanslı ve küçük genlikli (birkaç mm) salınımları kaydetmek için kullanılabilmektedir. Bu kapasitesi ile RTS, rüzgar veya trafik yükü etkisinde ki büyük mühendislik yapılarının izlenmesi için kullanilabilmektedir (Psimoulis ve Stiros, 2007; Pytharouli ve Stiros, 2008; Garget, 2015).

\subsection{RTS'de Hata Kaynakları}

TS ölçümleri sıcaklık, basınç ve bağıl nemdeki değişikliklerden etkilenir, ancak sıcaklık, basınç ve bağıl nemde değişiklikler atmosferik etkiler için düzeltilebilir. Şok ve stres ölçüm sapmalarına neden olur, sonuç olarak ölçüm doğruluğunu azaltır. Işın kesintileri, şiddetli 1s1 yansıması ve kiriş yolundaki nesnelerin hareket etmesi sapmalara neden olabilir. $\mathrm{Bu}$ nedenle ölçmeden önce aleti kontrol etmek ve ayarlamak önemlidir.

Bir prizmanın pozisyonunun Otomatik Hedef Tanıma (Automatic Target Recognition ATR) ile belirlenebildiği doğruluk, iç ATR doğruluğu, alet açısı doğruluğu, kullanılan prizma tipi, seçilen mesafe ölçüm programı ve dış ölçüm koşulları gibi çeşitli faktörlere bağlıdır. ATR, $\pm 1 \mathrm{~mm}$ 'lik bir standart sapma seviyesine sahiptir; ancak belli bir mesafenin üstünde, alet açısı doğruluğu ATR 
kılavuzunun standart sapmasını artırır. Farklı prizmaları kullanmak da sapmalara neden olabilir ve bu nedenle ölçümün amacına bağlı olarak uygun bir prizma kullanmak önemlidir. Standart prizma ile mesafe ölçme doğruluğu reflektör tipine ve Tablo 1'de verilen ölçme moduna bağlıdır.

Tablo 1. Standart prizma ile ölçme doğruluğu

\begin{tabular}{|l|l|l|}
\hline $\begin{array}{l}\text { Elektronik } \\
\text { Mesafe Ölçme }\end{array}$ & $\begin{array}{c}\text { Standart } \\
\text { Prizma }\end{array}$ & $\begin{array}{c}\text { Ölçme } \\
\text { zamanı }\end{array}$ \\
\hline Standart & $1 \mathrm{~mm}+1.5 \mathrm{ppm}$ & $2.4 \mathrm{sn}$ \\
\hline Hızı & $3 \mathrm{~mm}+1.5 \mathrm{ppm}$ & $0.8 \mathrm{sn}$ \\
\hline
\end{tabular}

Bunun dişında aletle ilgili olan bazı genel ölçüm hataları şöyledir. Kolimasyon eksen (görüss hattı) hatası saptırılacak yatay açıyı etkiler ve hatalı doğrultu ölçümüne neden olur. Dikey eksen (eğme ekseni) hataları, TS'nin yatay ekseninin dikey eksene dik olmadığı durumlarda oluşur. Kompanzasyon endeksi hatası: Bir teodolit veya TS'nin titizlikle ayarlanmamasından kaynaklanan hatadır ve $200 \mathrm{~g}$ farklı ölçümler yapılarak giderilemez. Dikey Kolimasyon (dikey indeks) hatası: Dikey daire içindeki 0o ile 180o hattı dikey eksenle çakışmazsa dikey bir kolimasyon hatası oluşur. Bu sıfır noktası hatası, tüm dikey daire okumalarında mevcut ve yatay kolimasyon hatası gibi $200^{\mathrm{g}}$ fark ölçümü yapılarak giderilemez.

Elektro-optik uzaklık ölçerle yapılan jeodezik ölçmeler, atmosferik (troposfer ve iyonosfer) kırılmadan etkilenir ve uzunluk ölçümünde doğruluk \pm 1-2 ppm civarındadır. Jeodezik yükseklik ölçümünde ise $20 \mathrm{~m}$ uzunlukta; $\pm 1 \mathrm{~mm}$ doğruluğa ulaşılabilir. $\mathrm{Bu}$ çalışmada kullanılan Geodimeter 610S için doğruluk parametreleri Tablo 2'de verilmiştir.
Tablo 2. Total Station (Geodimeter 610S) için doğruluk parametreleri

\begin{tabular}{|l|l|}
\hline Açı ölçümü & $0.5^{\mathrm{cc}}$ \\
\hline $\begin{array}{l}\text { Otomatik Hedef Tanıma } \\
\text { Doğruluğu }\end{array}$ & $1^{\mathrm{cc}}$ \\
\hline Mesafe Ölçümü & $1000 \mathrm{~m}$ \\
\hline Hassas Mod & $0.6 \mathrm{~mm}+1 \mathrm{ppm}$ \\
\hline Standart Mod & $1 \mathrm{~mm}+1 \mathrm{ppm}$ \\
\hline $\begin{array}{l}\text { İzleme / Senkronize } \\
\text { İzleme Modu }\end{array}$ & $3 \mathrm{~mm}+1 \mathrm{ppm}$ \\
\hline
\end{tabular}

\section{3. Çalışma Alanı ve Test Ölçümleri}

Test çalışması, İstanbul'da bulunan $220 \mathrm{~m}$ yüksekliğinde bir kule'de gerçekleştirilmiştir. Test ölçğmleri, yapının $165 \mathrm{~m}$ yüksekliğine yerleştirilen iki adet GNSS alıcısı ve 2 adet RTS prizması kullanılarak gerçekleştirilmiştir. Şekil 1'de GNSS alıcıları ve RTS prizmalarının yakın görütleri sunulmuştur. Şekil 2'de ölçme sisteminin yandan görüntüsü şematik olarak gösterilmiştir.

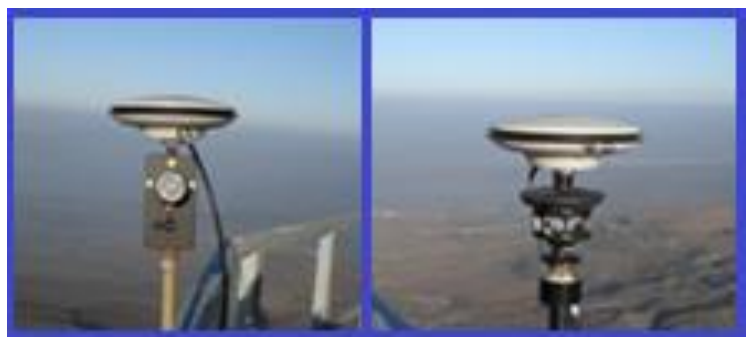

Şekil 1. GNSS antenleri ve RTS prizmaları 


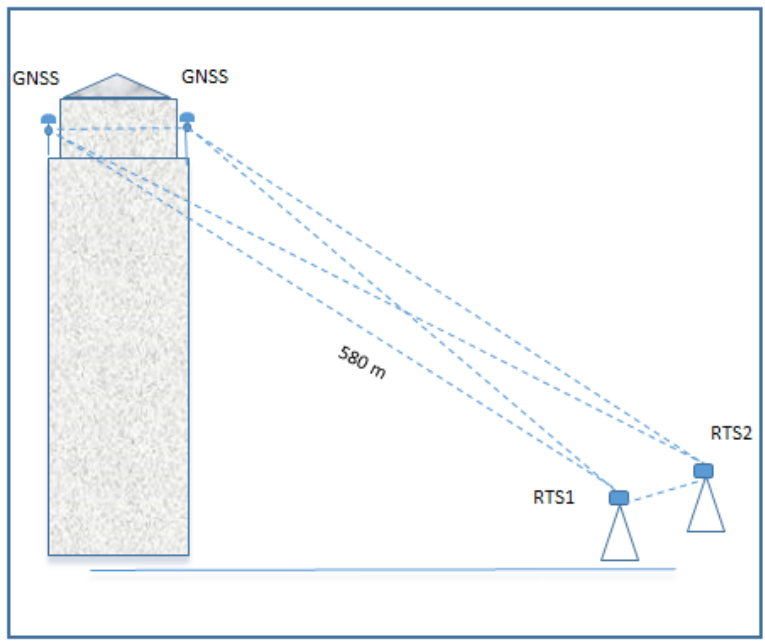

Şekil 2. Çalışma alanının şematik görünüşü.

\subsection{GNSS ile Ölçümler}

GNSS verisi $20 \mathrm{~Hz}$ örnekleme oranı ile Novatel GNSS alıciları kullanılarak kaydedilmiştir. Öncelikle, gözlem serileri \pm 5 $\mathrm{cm}$ threshold ile kaba hatalardan ayıklanmıştır. Her 1 saniyede 20 adet veri kayıt edilerek elde edilen GNSS serileri, -10 ve +10 adet nokta ortalamaları alınarak 1 sn örnekleme aralığı ile yeniden örneklenmiştir. Her iki GPS alıcisindan elde edilen veri, ECEF (Earth-Centered, Earth-Fixed) koordinat sisteminde kayıt edilmiştir. Değerlendirmede kolaylık sağlaması için, Lokal topocentric coordinates (LTC) sistemine dönüştürülmüştür (Pehlivan, 2009; Pehlivan ve Bayata, 2014).

\subsection{Total Station ile Ölçümler}

$\mathrm{Bu}$ çalışmada, sürekli izleme için robotik teodolitler gerektiğinden, servo motorlu iki adet Geodimeter 600S total stationlar kullanılmıştır (Şekil 3-b). Bu aletler, servo motoru ve ATR sensör özellikleri ile dürbününü otomatik olarak yönlendirerek, belirli zaman aralıklarında yatay - düşey doğrultu açılarını ve mesafe okumalarını otomatik olarak kayıt etmiştir (Şekil 3-a). Ölçümlerin gerçekleştirildiği prizmalar Şekil 1'de gösterildiği gibi binaya monte edilmiştir. Kule üzerinde iki noktada tesisi yapılan GNSS antenleri ile aynı düşey doğrultuda Şekil 1'de görüldüğü gibi iki adet prizma eklenmiştir.

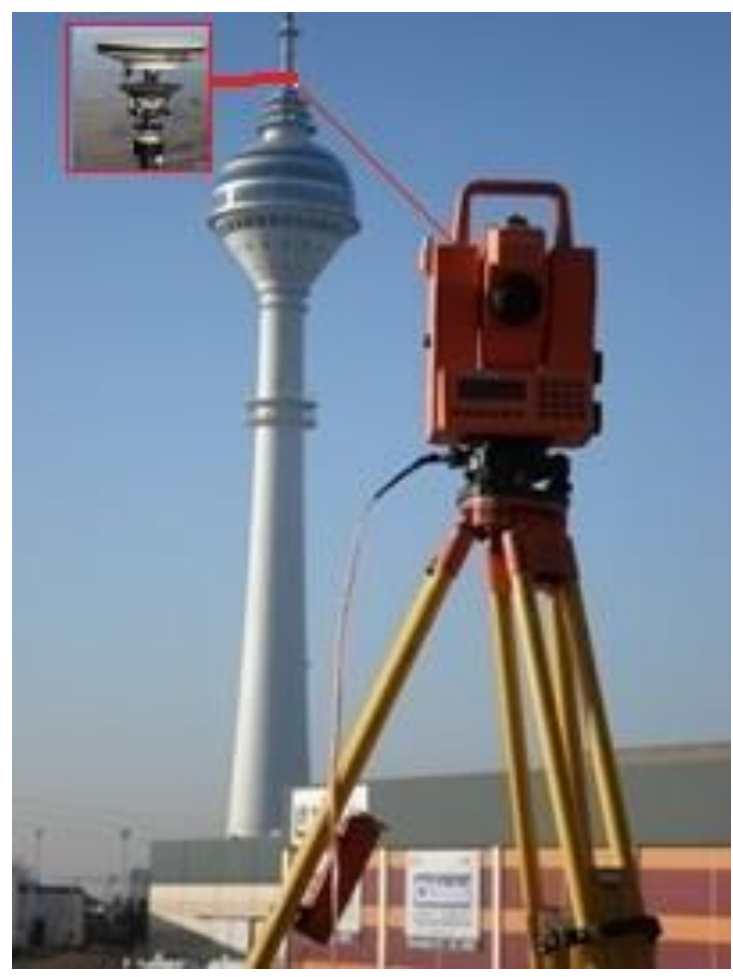

(a)

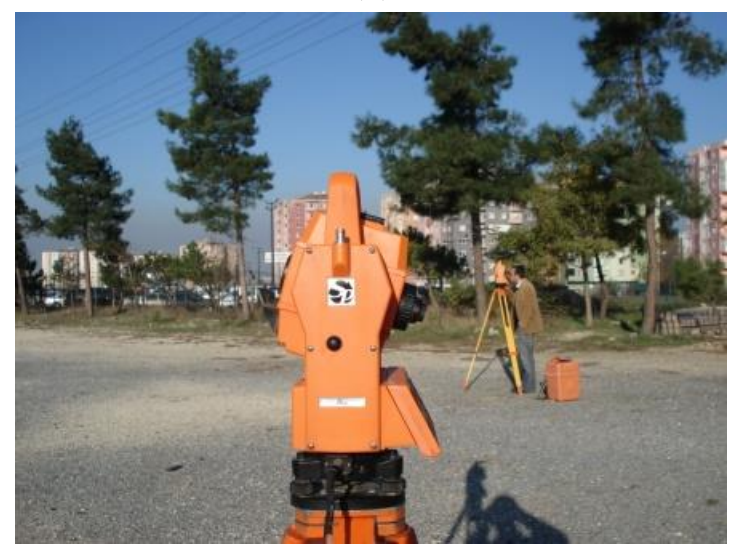

(b)

Şekil 3 a) RTS ile yapısal izleme, b) RTS

Geodimeter 600S aletinin dahili hafizasında çalışan program " 65 " ve "66" kullanılmıştır. Geodiemeter 600S aleti bu program ile periyodik olarak reflektörlere yönelmiş ve okumaları kayıt etmiştir. Kayıt edilen örnek ham veri ölçüleri Tablo 3 'te gösterilmiştir. 
Tablo 3. Geodimeter 600S ile kayıt edilen veri format1

\begin{tabular}{|c|c|c|c|c|c|c|c|c|}
\hline $\begin{array}{c}\text { Hedef } \\
\text { No }\end{array}$ & $\begin{array}{c}\text { Tarih } \\
\text { (yl.ay.gün) }\end{array}$ & Zaman & $\begin{array}{c}\text { Yatay } \\
\text { Doğrultu } \\
\text { (gon) }\end{array}$ & $\begin{array}{c}\text { Düşey } \\
\text { Açı (gon) }\end{array}$ & $\begin{array}{c}\text { Eğik } \\
\text { Uzaklık } \\
(\mathbf{m})\end{array}$ & $\begin{array}{c}\mathbf{X} \\
(\mathbf{m})\end{array}$ & $\mathbf{Y}$ & $\mathbf{Z}$ \\
\hline 1 & 2017.10 .12 & 12.00 .20 & 91.8002 & 81.8192 & 580.507 & 110.575 & 137.820 & 265.021 \\
\hline 2 & 2017.10 .12 & 12.00 .34 & 90.3326 & 81.8393 & 580.516 & 120.115 & 134.474 & 264.911 \\
\hline 1 & 2017.10 .12 & 12.02 .02 & 91.8006 & 81.8195 & 580,507 & 110.576 & 137.819 & 265.017 \\
2 & 2017.10 .12 & 12.02 .26 & 90.3324 & 81.8396 & 580.516 & 120.112 & 134.475 & 264.909 \\
$\ldots$. & $\ldots$. & $\ldots$. & $\ldots$ & $\ldots$. & $\ldots$. & $\ldots$. & $\ldots$ & $\ldots$. \\
\hline
\end{tabular}

\section{Veri Analizi ve Metodoloji}

GNSS ve RTS alıcıları kullanılarak 6 saat süresince eşzamanlı olarak gerçekleştirilen gözlem serileri incelenmiştir. GNSS ve TS ile elde edilen gözlem serilerinden konum değişimlerinin hesaplanması için bir dizi işlem gerçekleştirilmiştir. Öncelikle veride ki gürültü ve kaba hatalı ölçüler alçak geçiren filtre ile fast fourier dönüşümü (FFT) ile filtrelenmiştir. Bütün seriler veri atlamaları ve zaman uyumu için 1 saniye ile yeniden örneklenmiştir. Bütün gözlem serilerine alçak geçiren filtreleme uygulandiktan sonra Fast Fourier Transformation kullanılarak frekans değerleri hesaplanmıştır. Bütün sinyaller baskın frekans değerleri kullanılarak, Ters Fourier Eşitliği ile zaman bölgesinde yeniden oluşturulmuştur. $\mathrm{Bu}$ yeni sinyaller gözlem serilerinin yeni model serileri olarak değerlendirilmiştir. Konum değişimlerinin, $X-Y$ düzleminde üst üste görülebilmesi için, her iki yöntemle elde edilen zaman serileri aynı koordinat sistemine dönüştürülmüştür. (Pehlivan, 2013; Xua vd., 2002).

Şekil 4'te GNSS ve RTS ölçümleri ve hesaplanan model fonksiyonları sunulmuştur. Şekilden de görüldüğü üzere, GNSS zaman serilerinden $\mathrm{cm}$ seviyesine varan genlikler, RTS zaman serlerinden $\mathrm{mm}$ inceliğinde görülmektedir. Belirlenen genlik büyüklükleri, aynı yönlü ve mm seviyesinde farklılıkla belirlenmiştir.

Ölçümlerin hassasiyet ve doğruluğunu belirlemek için, bireysel ölçümlerin RMS (root mean square error) ve standart sapmaları hesaplanmıştır. $\mathrm{Bu}$ çalışmadaki referans ağ koordinatları $1 \mathrm{~mm}$ seviyesinde belirlenen doğrulukla kabul edilmiştir. RMS değerleri aşağıda verilen eşitlik kullanılarak hesaplanmıştır.

$\operatorname{RMS}(\mathrm{l})=\sqrt{\sum_{\mathrm{i}=1}^{\mathrm{n}} \frac{\left(\mathrm{l}-\mathrm{l}_{\mathrm{i}}\right)}{\mathrm{n}}}$

Eşitlik 1.'de; l belirlenen değerdir, li bireysel ölçümdür ve $n$ ölçüm sayısıdır. Ayrıca hesaplanan standart sapma değerleri, tekrar eden ölçümlerin değişim derecesinin bir ölçüsü olarak düşünülmüştür. Her bir bireysel gözlem değerinin doğruluğu olarak, her bir ölçüm setinin ortalama değerinden hesaplanmıştır. 


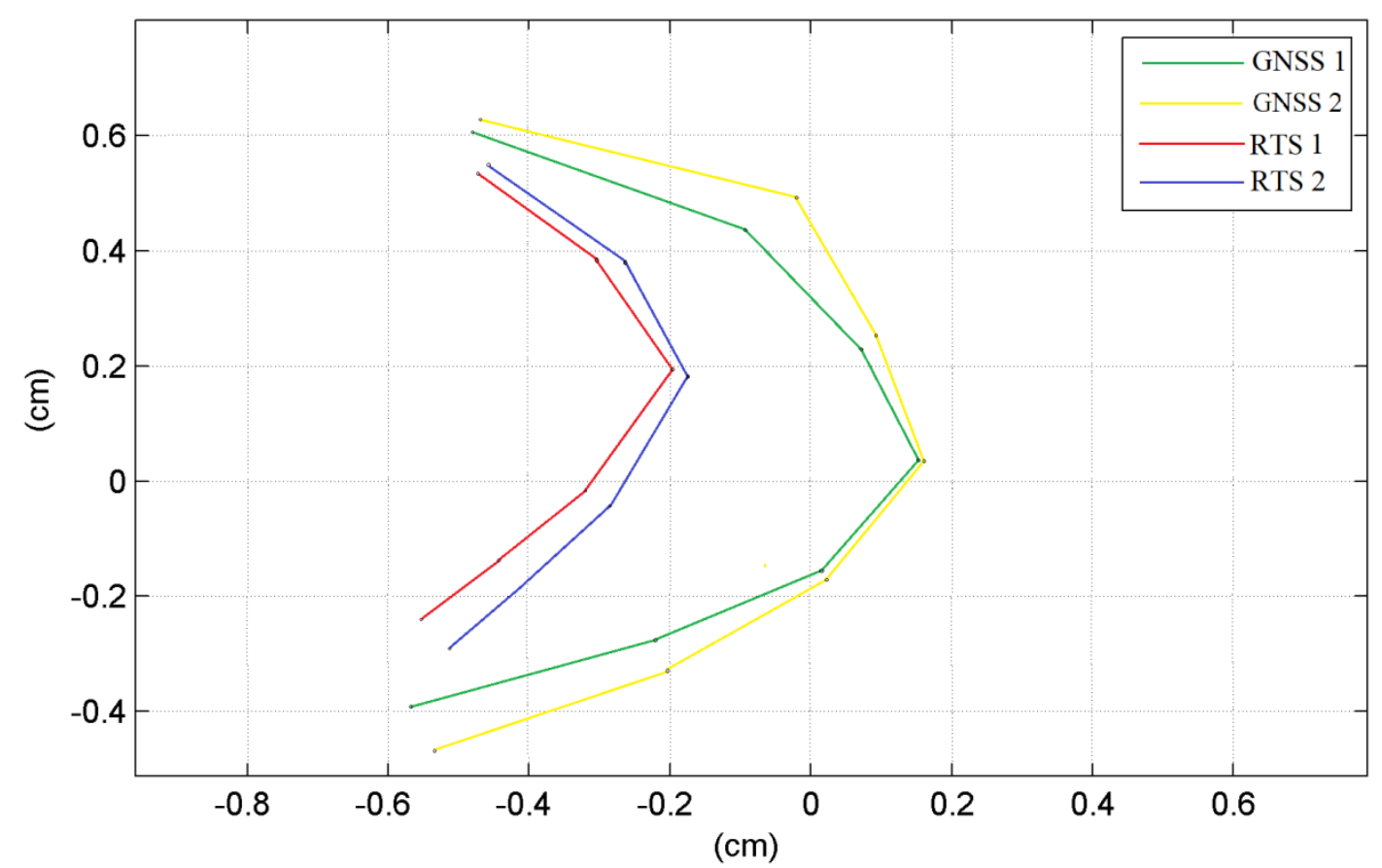

Şekil 4. GNSS ve RTS ölçümlerinden elde edilen genlik-konum değişimleri

\section{Sonuç}

GNSS ve RTS verilerinin değerlendirilmesi amacıyla, GNSS alıcılarının yapının her iki tarafina monte edilmiş olması, aynı anda farklı uydu geometrilerini kullanmalarına ve farklı multipath hataları içermelerine neden olmuştur. RTS prizmalarıda GNSS alıcıları ile aynı doğrultuda konumlandırılmış ve böylece bütün alıcıların birbirini tamamlayıcı nitelikte olması sağlanmıştır. Elde edilen eşzamanlı veriler incelendiğinde, GNSS zaman serilerinin yüksek frekanslı bileşenleri $\pm 2 \mathrm{~mm}$ seviyelerinde rastgele salınımlar gösterirken, RTS zaman serlirinin yüksek frekanslı bileşenleri $\pm 0.1 \mathrm{~mm}$ seviyelerinde salınımlar göstermektedir. GNSS ve RTS serileri işlendikten sonra aynı koordinat sistemine dönüştürülerek $\mathrm{X}-\mathrm{Y}$ ekseninde gösterilmiştir. Şekil 4'te, GNSS ve RTS alıcıları ile $16 \mathrm{~mm}^{2}$ lik alanda konum değişimi gösterilmiştir. Buna göre sürekli yapısal izlemelerde RTS'nin doğruluk performansı dinamik yapısal hareketleri $\mathrm{mm}$ seviyesinde belirlemek için yeterlidir. Bunun yanında hareketin statik ve yarı statik bileșenlerini belirlemek mümkün değildir. RTS ile Z ekseni yönündeki yerdeğişimlerini belirlemekte mümkün olmamaktadır. Buna karşılık GNSS statik, yarı-statik ve dinamik yap1 davranışlarını belirlemekte kullanılabilir.

Kayıt edilen zaman serilerinin frekans alanında spektral analizi gerçekleşirilerek şu sonuçlar elde edilmiştir; GNSS ile cm doğrulukla en az 0.5-1 cm genlikli salınımlar belirlenebilirken, RTS ile birkaç $\mathrm{mm}$ doğrulukla $(2 \mathrm{~mm})$ genlikli salınımlar kayıt edilebilmiş ancak yüksek frekanslı hareket değerleri belirlenememiştir. $\mathrm{Bu}$ sonuçlar otomatize edilen Elektronik Totalstationların GNSS' lere bir alternatif olarak yap1 deplasmanlarının belirlenmesinde kullanılabileceğini göstermiştir. 


\section{Kaynaklar}

Brownjohn, J., Rizos, C., Tan, G. H. and Pan, T. C., "RealTime Long-Term Monitoring of Static and Dynamic Displacements of an Office Tower, Combining RTK GPS and Accelerometer Data", 1st FIG International Symposium on Engineering Surveys for Construction Works and Structural Engineering, Nottingham, UK, 28 June-1 July 2004.

Chan W.S. Xu Y.L. Ding X.L. Dai W.J. 2006. "An integrated GPS-accelerometer data processing technique for structural deformation monitoring", J. Geodesy, 80, 705-719.

Erol B. 2010. "Evaluation of High-Precision Sensors in Structural Monitoring", Sensors, 10, 10803-10827.

Garget, D. 2015 “ Testing of Robotic Total Stations For Dynamic Tracking", Bachelor Thesis, University of Southern Queensland Faculty of Engineering and Surveying, Toowoomba, Australia.

Ge, L., Han S., Rizos C., Ishikawa Y., Hoshiba M., Yoshida Y., Izawa M., Hashimoto N., and Himori S, 2000. "GPS seismometers with up to $20-\mathrm{Hz}$ sampling rate", Earth Planets and Space, 52(10): 881-884.

Greulich, G. 1997. "Dynamic deformation monitoring of tall structure using GPS technology - Discussion", Journal of Surveying Engineering-Asce, 123(1), 49-50.

Guo, J., Xu, L., Dai, L., McDonald, M., Wu, J., Li, Y., 2005. "Application of the real-time kinematic Global Positioning System in bridge safety monitoring”, Journal of Bridge Engineering, 10(2), 163-168.
Izvoltova J., Villima, A., Kozak P. 2014. "Determination of Geometrical Track Position by Robotic Total Station", Procedia Engineering, 91, $322-327$.

Kontogianni, V., Kornarou, S., Stiros, S. 2007. "Monitoring with electronic total stations: Performance and accuracy of prismatic and non-prismatic reflectors", Geotech, 25, 30-37.

Lienhart W., Ehrhart M., and Grick M. 2016. "High frequent total station measurements for the monitoring of bridge vibrations", $\mathrm{J}$. Appl. Geodesy, 11, 1-8.

Moschas, F., Stiros, S. 2011. "Measurement of the dynamic displacements and of the modal frequencies of a short-span pedestrian bridge using GPS and an accelerometer", Engineering Structures, 33, 10-17.

Moschas, F., Psimoulis, P. and Stiros, S. 2013. "GPS-RTS data fusion to overcome signal deficiencies in certain bridge dynamic monitoring projects", Smart structures and systems 12 (3-4), 251-269.

Psimoulis, P. and Stiros, S. 2008. "Experimental Assessment of the Accuracy of GPS and RTS for the Determination of the Parameters of Oscillation of Major Structures", Computer-Aided Civil and Infrastructure Engineering 23 (5), 389-403.

Pehlivan, H. and Bayata, H. F. 2014. "Comparison of GPS and Inclinometer Data in Structural Monitoring", the First International Conference on Engineering and Applied Sciences Optimization (OPT-i), the Island of Kos, Greece, on 4-6 June 2014. ISSN: 2241-9098, ISBN: 978-960-99994-5-8

Pehlivan, H., 2013. "Spectral Analysis of Real-Time Kinematic GPS Data", Harita 
Dergisi, 2013/149, Harita Genel Stiros, S., Psimoulis, P., Kokkinou, E., 2008.

Komutanlığg, Ankara, Turkiye.

Pehlivan, H., 2009. "The Investigation of Dynamic Behaviors in Structures With RealTime Kinematic GPS", PhD Thesis, Fen Bilimleri Enstitüsü, Yildiz Technical University, Istanbul, Turkiye.

Psimoulis, P., Stiros, S., 2011, "Robotic Theodolites (RTS) Measuring Structure Excitation, GIM International", 25(4), 29-33.

Psimoulis, P., Pytharouli, S., Karambalis, D., Stiros, S., 2008, "Potential of Global Positioning System (GPS) to measure frequencies of oscillation of engineering structures", Journal of Sound and Vibration 318(3), 606-623.

Psimoulis, P., Stiros, S., 2008, "Experimental assessment of the accuracy of GPS and RTS for the determination of the parameters of oscillation of major structures", ComputerAided Civil and Infrastructure Engineering, 23, 389-403.

Psimoulis, P., Stiros, S., 2007. "Measurement of deflections and of oscillation frequencies of engineering structures using Robotic Theodolites (RTS)", Engineering Structures, 29 (12), 3312-3324.

Pytharouli, S., Stiros, S., 2008. "Spectral Analysis of Unevenly Spaced or Discontinuous Data Using the 'Normperiod' Code", Computers and Structures, 86 (1-2), 190-196.

Stiros, S. and Psimoulis, P., 2012. "Response of a historical short-span railway bridge to passing trains: 3-D deflections and dominant frequencies derived from Robotic Total Station (RTS) measurements", Engineering Structures, 45, 362-371.
"Errors introduced by fluctuations in the sampling rate of automatically recording instruments: Experimental and theoretical approach", Journal of Surveying Engineering, 134(3), 89-93.

Schofield, W., Breach, M., (2007). "Engineering Surveying", UK, Elsevier Ltd., 622 pp. ISBN 978-0-7506-6948-8.

Xia, H., and Zhang, N., 2005. "Dynamic Analysis of Railway Bridge under Highspeed Trains", Computers and Structures, 83, 1891-190.

Xu, L., Guo J., , Jiang J., 2002. "Timefrequency analysis of a suspension bridge based on GPS", Journal of Sound and Vibration, 254 (1), 105-116. 